\section{Book Reviews}

\section{GROWTH CYCLES}

\section{Is the Business Cycle Obsolete?}

Edited by M. Bronfenbrenner. Pp. xii +567 . (Wiley (Interscience): London and New York, March 1970.) $120 s$.

Economists and economic historians have long been fascinated by the way in which economic activity tends to fluctuate over time, and many theories have been put forward to explain cyclical behaviour. The papers in this volume (an outcrop of a conference held in London in April 1967) are primarily concerned, however, with the question of whether the business cycle is now defunct. The selection includes a number of case studies of individual countries, both capitalist and socialist, three econometric studies and two general articles on business cycle policies and the transmission of fluctuations from developed to underdeveloped countries. It is an impressive collection of papers written by distinguished scholars.

The goneral consensus of opinion seems to be that business cycles are still with us but that their characteristics are somewhat different from those before the war. Broadly speaking, cycles are shorter and less intense than they were previously, and in many cases high floors in the downswing have resulted in what might be termed "growth cycles" in which the recessions are characterized by decelerations in rates of growth rather than by absolute contractions in eeonomic activity. Even these modified cycles may be on the way to extinction given the progress in macroeconomic and econometric model building and forecasting.

It is impossible to summarize briefly the great deal of information contained in this volume and, in any case, there is a long and very competent survey of the whole proceedings by the editor at the end of the volume. Unfortunately, the discussion of the debate is on a chapter by chapter basis, and only a very sketchy attempt is made to draw the common threads together in the preface. This is a serious shortcoming, because the contributions do vary a great deal in quality, scope, methodology, and in their conclusions. The most useful paper is Bert Hickman's elegant survey of econometric models, while the least informative are those by Nove on the Soviet Union and by Dow on Franee, Germany and Italy. Only a few authors put the post-war cycle in its long-term historical context, and in this respect Professor Matthews's paper on Britain is one of the best. The methods used to measure the amplitude of cycles and date their turning points vary considerably, and it is a pity that some effort was not made to achieve a greater degree of uniformity in this matter. Rather surprisingly, there is no specifie paper dealing with the transmission of cycles among developed countries-a rather serious omission in view of the fact that it would have helped to clarify the issue of the relative mildness of the post-war cycle. Fortunately, an excellent chapter by Kurt Rothschild on Austria and Switzerland, a title which somewhat belies the wider context in which it is set, helps to repair this gap to some extent.

Perhaps the chiof defect of the volume stems from the fact that the authors have been too concerned with presenting the facts and relating these to the conference title, to the ultimate neglect of analysing the reasons for the changes in eyclical characteristics in the post-war period. Nevertheless, the work as a whole provides a useful insight into the type of business cycle research now in progress.

Derex H. AldCroft

\title{
URBAN DEVELOPMENT
}

\section{Developing Patterns of Urbanization}

Edited by Peter Cowan. (Centre for Environmental Studies.) Pp. vi +216. (Oliver and Boyd: Edinburgh, February 1970.) $40 s$.

Economic, social and physical development is proceeding so fast now that the importance of forecasting the future is being understood to an increasing extent. This volume contains an attempt by a group of specialists in fields related to urbanization to explore to what extent guidance can be given in this subject by a forecast of possible future developments. This has resulted in a collection of essays which, according to one contributor, "amounts to a lightly disciplined excrcise in intuitive thinking; hopefully the next phase will introduce greater rigour and sharper purpose" (D. Bayliss). This is a somewhat modest statement, underestimating perhaps the significance of fascinating and thought provoking contributions. To forecast the future is indeed a difficult task, and it is not surprising that a group of distinguished writers does not necossarily reach a consensus of opinion; it may be judged in fact to be one of the merits of the essays that the reader is presented with differing alternatives, and so encouraged, if he is interested in and concerned with urban problems, to evolve his own interpretations.

It seems very likely that the broad pattern of urbanization, which has not been changed much in the geographic sense during the past 50 or even 500 years, will look not so very different in AD 2000 , existing investment in the built environment being a compelling constraint (E. Jones and P. A. Stone). Bosides, people are not prepared to spend as much on housing as they do, for instance, on motoring, and may well favour a greater output of restored and reconditionod dwellings which can be produecd quicker and cheaper and will therefore command lower rents. In any case, there are doubts as to whother the space economy practised since the Second World War has produced housing which will be sufficiently adaptable for future needs; the oldest section of the housing stock will probably not be the first social slums of the near future (C. Price). But the expected population growth cannot be accommodated entirely in existing cities, nor, with some exceptions, in self contained new cities: it will have to be retained in the suburban ring of existing metropolitan areas (P. Hall). Such a pattern will meet the clear demand for more space both near the home and in a not too distant countryside; it will permit central decongestion and follow well established trends of decentralization along fast transportation radials on a regional scale and perhaps reconcentration at the local suburban scale. Such a trend may be accelerated by developing traffic technology, increasing speeds and improved telecommunications (P. Cowan).

Considerable changes in life styles and activities can take place, however, without a change in the physical pattern of our urban areas. There seems to be a growing popularity of family life related to a shift towards the home and marriage partnership. More people, including skilled and unskilled manual workers, buy their own homes. People get married much earlier, which means that their grown up children will leave them on their own for very much longer periods than was the case in earlier generations (P. Wilmot). But, whereas at the child rearing age suburban homes may be preferred, at the subsequent 